tation TLC (Fig. 2). The most unsaturated fraction was isolated and partially hydrolyzed with pancreatic lipase (EC 3.1. 1. 3). The reaction proceeded in the same manner as that of authentic dimethyl phosphatidate; free fatty acids and lysophosphatidic acid dimethyl esters as well as intact starting material were found in both reaction mixtures. The lysolipid formed from the herring derivative contained about equal amounts of 20:5 and 22:6; these are C-2 fatty acids according to the model experiment. The free fatty acid fraction of the hydrolysate was almost pure 22:6 with traces of 20:5. This fraction represents $\mathrm{C}-1$ acids according to the model experiment. Thus the principal molecular species of the slow fraction must have been dimethyl phosphatidates of the structure 22:6$20: 5$ and $22: 6-22: 6$.

\section{ACKNOWLEDGMENTS}

This work was aided in part by grants from the Sigrid Jusélius Foundation, Helsinki, and from the University of Helsinki. Technical assistance given by Mrs. Anneli Asikainen and Mrs. Satu Liusvaara.

\section{OSSI RENKONEN \\ Department of Serology and Bacteriology University of Helsinki Finland}

\section{REFERENCES}

1. Renkonen, O., Adv. Lipid Res. 5, 329-351 (1967).

2. Renkonen, O., JAOCS 42, 298-304 (1965),

3. Renkonen, O., Biochim. Biophys. Acta 137, 575-577 (1967).

4. Wurster, C. F., and J. H. Copenhaver Jr., Lipids 1, 422-426 (1966).

[Received Aug. 17, 1967]

\title{
Lipid Contaminants: Polypropylene Apparatus and Vacuum Pumps
}

Several reports have been issued on lipid $\mathcal{S}$ contaminants from various laboratory sources, such as vacuum pump exhausts, cigarette smoke, hand cream, rubber tubing, and others (1); plastic bags, probably vinyl (2); and polyethylene bottles (3). It has been shown that dry adsorbent powders can take up lipids from plastic containers without the intervention of a solvent. (It appears that adsorbent manufacturers are still disregarding this source of contamination.) Tygon tubing and related brands of vinyl tubing have been known to contribute their plasticizers to solvents.

To this list must be added polypropylene. This plastic is often described as resistant to organic solvents, but we have noted that several lipids are rapidly extracted from graduated polypropylene cylinders when they are used to measure out methanol, chloroform, or hexane. The lipids are readily detected on evaporating the solvents to dryness. Thinlayer chromatography on Silica Gel $G$ with hexane-ether $(85 / 15)$ disclosed seven spots, detected with alkaline bromothymol blue. The $\mathbf{R}_{\mathrm{f}}$ values (multiplied by 100 ) were $0,3,20$, $23,28,75$, and 80 . The numbers in italics refer to the more intense spots. The contaminants have not been identified, but we know from the fabricator of the cylinders that antioxidants are added to the plastic.
We thought that prolonged soaking might leach out the contaminants, thus making the cylinders usable in lipid work. Two four-day periods of standing with chloroform-methanol (1:1) yielded much solid matter in both extracts. By this time the cylinders were no longer straight, and the attempt was discontinued. It is possible that apparatus of less sensitive shape could be cleaned up adequately by sufficient soaking.

The problem of vacuum pump oil contamination of laboratory atmospheres can be eliminated quite nicely by attaching filters to the pump exhausts. These filters are available from the Arthur H. Thomas Company. They are excellent also for decreasing the noise of vacuum pumps.

\author{
NORMAN S. RADIN \\ LISELOTTE HOF \\ CAROLYN SEIDL \\ Mental Health Research Institute \\ University of Michigan \\ Ann Arbor, Michigan 48104
}

\section{REFERENCES}

1. Rouser, G., G. Kritchevsky, M. Whatley and C. F. Baxter, Lipids 1, 107-112 (1966).

2. Bauman, A. J., R. E. Cameron, G. Kritchevsky and G. Rouser, Lipids 2, 85-86 (1967).

3. Ma, J. C. N., J. Chromatography $21,151-154$ (1966)

[Received Nov. 14, 1967] 